\title{
Pneumonectomy for lung metastases: the role in the modern era
}

\author{
Alessio Vincenzo Mariolo, Madalina Grigoroiu, Agathe Seguin-Givelet, Emmanuel Brian, Dominique \\ Gossot, Philippe Girard
}

Thoracic Department, Curie-Montsouris Thoracic Institute, Institut Mutualiste Montsouris, Paris, France

Contributions: (I) Conception and design: AV Mariolo; (II) Administrative support: AV Mariolo; (III) Provision of study materials or patients: AV Mariolo, M Grigoroiu, A Seguin-Givelet; (IV) Collection and assembly of data: AV Mariolo, M Grigoroiu, A Seguin-Givelet; (V) Data analysis and interpretation: AV Mariolo, M Grigoroiu, P Girard; (VI) Manuscript writing: All authors; (VII) Final approval of manuscript: All authors.

Correspondence to: Alessio Vincenzo Mariolo. Thoracic Department, Curie-Montsouris Thoracic Institute, Institut Mutualiste Montsouris, 42 Boulevard Jourdan, 75014 Paris, France. Email: mariolo.alessio@gmail.com.

\begin{abstract}
Lung metastasectomy is considered worldwide as part of multimodal treatment for selected oligometastatic patients. Wedge resection is the most common approach performed with lung-sparing intent and, even if anatomical resections like segmentectomies or even lobectomies can be accepted, the role of pneumonectomy has always been debated and progressively discouraged due to the perceived high morbidity and mortality rates compared with its uncertain oncological benefits. A retrospective review and analysis of patients underwent pneumonectomy for lung metastases conducted in our center from January 1995 to December 2017 showed that on a total of 832 pneumonectomies performed, only 17 (2\%) were conducted to resect pulmonary metastases and above all, only two patients were operated in the last decade. This revealed the tendency to progressively abandon the use of pneumonectomy to treat pulmonary metastasis. Indications and outcomes of pneumonectomy to resect pulmonary metastases are illustrated along with the speculative reasons of the decrease in the use of this therapeutic tool. The latter include a better patient selection due to the improved understanding of the oligometastatic disease, major improvements in the efficiency and tolerance of systemic therapies and the availability of alternative techniques for the local treatment of secondary lung lesions. Nevertheless, the limited benefit in terms of long-term survival and the relative high morbidity and mortality should not exclude a priori from considering pneumonectomy with curative intent for locally-advanced metastatic disease. A tiny role for this option is likely to remain in the therapeutic armamentarium for highly selected patients with isolated resectable pulmonary metastases undergoing a multidisciplinary management when no other alternatives are available.
\end{abstract}

Keywords: Lung metastases; metastasectomy; pneumonectomy; oligometastatic disease

Received: 26 November 2019; Accepted: 23 December 2019; Published: 10 April 2020.

doi: $10.21037 /$ shc.2019.12.04

View this article at: http://dx.doi.org/10.21037/shc.2019.12.04

Since the publication of the landmark report of the International Registry of Lung Metastasetomy (IRLM) in 1997 (1), pulmonary metastasectomy has been recognized as a therapeutic option with intent of cure in selected patients. Even if there are still no adequately powered prospective randomized trials that compare pulmonary metastasectomy to medical treatment or observation (2), the most significant experiences in the literature emphasize the importance of patient selection in the context of oligometastatic disease and the imperative of achieving a complete eradication of all metastatic lesions while limiting as much as possible the volume of resection to achieve the lowest necessary morbidity (3). In this context, the role of extended pulmonary resections and in particularly of pneumonectomy has been largely debated (4). In fact, the notable high complication and mortality rates (5) along with the relatively limited reported oncological benefits have strongly discouraged this practice. The aim of this study is to place pneumonectomy in the context of oligometastatic disease, to explore and comment the 
Table 1 Literature background (main series reporting on pneumonectomy for lung metastases)

\begin{tabular}{|c|c|c|c|c|}
\hline Study & Year of publication & Number of patients & Mortality (\%) & 5-year overall survival (\%) \\
\hline Putnam et al. & 1993 & 19 & 10.5 & 25 \\
\hline Spaggiari et al. & 1998 & 42 & 7 & 17 \\
\hline Koong et al. & 1999 & 133 & 6 & 23 \\
\hline Casiraghi et al. & 2015 & 14 & 0 & 27 \\
\hline Matsutani et al. & 2017 & 55 & 6 & 29 \\
\hline Our experience & 2019 & 17 & 6 & 29 \\
\hline \multicolumn{5}{|c|}{ Completion pneumonectomy } \\
\hline Chataigner et al. & 2008 & 11 & 0 & 41 \\
\hline Jungraithmayr et al. & 2004 & 9 & 0 & $34 \%$ at 3 years \\
\hline
\end{tabular}

reasons for its decline in clinical practice, in order to delineate the possible role of pneumonectomy for lung metastasectomy in the modern era.

\section{Definition, indications, literature background and our experience}

Pneumonectomy represents the surgical resection of a whole lung and can be divided in primary and completion pneumonectomy. The former is performed as an elective procedure while the latter represents the last surgical act, after one or more previous operations (6). Indications to resort to an elective pneumonectomy are typically represented by one or more secondary lesions that cannot be otherwise resected assuring free margins-i.e., centrally located metastases involving both the superior and the inferior lobe, or lesions that critically compromise the fissure or the hilar structure. Completion pneumonectomy is performed to remove the entire remaining parenchyma after previous surgical resections and it is mainly indicated in unilateral recurrences when smaller resections would not leave enough functional parenchyma (7). The literature concerning the role of pneumonectomy to resect lung metastases is composed by sporadic case reports or small series, mostly published between 1995 and 2003 reporting very heterogeneous data (8-16). A selection of these studies is presented in Table 1. All data, except for the report published by Koong (10), derived from single institutions' experiences based on subsets of fewer than 40 patients, reporting operative mortality rates between $0 \%$ and $10.5 \%$, and 5 -year survival rates ranging from $17 \%$ to $39 \%$. Such data may appear discouraging if compared with those from large series of lung-sparing resections, mostly wedge resections, with reported mortality rates between $0 \%$ and $2.5 \%$ and overall 5 -year survival rates ranging from $20 \%$ to $48 \%$, which can reach $56 \%$ for sarcoma patients and $82 \%$ for colorectal cancer (17-20). In 1998, a series from our center reported on 42 patients who underwent pneumonectomy for lung metastases between 1985 and 1995 (9). In the presented study we present data retrospectively collected with the ideal intent of proceed in the published experience. From 1995 to 2017, 831 consecutive patients underwent pneumonectomy in our center, and only 17 procedures were conducted for pulmonary metastases (2\%). Data on clinical and surgical characteristics are specified in Table 2. One patient died on postoperative day 29 because of pulmonary edema, 3 patients (18\%) had minor complications treated medically, and 3 patients (18\%) had major complications (2 empyema and 1 hemothorax) which required a second surgical intervention (Table 3). The median survival time after resections was 30 (range 1 to 144) months and the overall 5 -year survival rate was $29.4 \%$. Such data are not dissimilar from the results reported in the literature, but they highlight a dramatic decrease in the number of pneumonectomies for metastatic 
Table 2 Clinical and surgical characteristics patients who underwent pneumonectomy for lung metastases in our experience

\begin{tabular}{lll}
\hline Characteristics & N & $\%$ \\
\hline Sex & 8 & \\
Men & 9 & 47 \\
Women & & 53 \\
Age & 5 & \\
$<50$ & 4 & 29 \\
$50-59$ & 8 & 24 \\
$>59$ & & 47
\end{tabular}

\section{Side ${ }^{a}$}

Right

Left

$7[1]^{\mathrm{a}}$

Primary tumor

Epithelial $^{\mathrm{b}}$
Sarcoma

Melanoma

Number of metastases

$\begin{array}{lll}1 & 8 & 47 \\ 2 & 5 & 29 \\ 3+ & 4 & 24\end{array}$

Nodal status

$\begin{array}{lll}\text { No } & 5 & 29 \\ \text { N1 } & 3 & 18 \\ \text { N2 } & 9 & 53\end{array}$

FEV1 (\%)

\begin{tabular}{lll}
$<75$ & 5 & 29 \\
$75-90$ & 4 & 24 \\
$90-100$ & 3 & 18 \\
$>100$ & 2 & 12 \\
Unknown & 3 & 18 \\
DFI & & \\
$<5$ years & 12 & 71 \\
$>5$ years & 5 & 29 \\
\hline
\end{tabular}

a, In parenthesis the completion pneumonectomies; ${ }^{b}$, five colorectal carcinoma, two renal carcinoma, one bladder carcinoma, two uterine carcinoma, one prostate carcinoma, one breast cancer, one adrenal gland carcinoma. FEV1, forced expiratory volume in 1 second; DFI, Dougados functional index.
Table 3 Postoperative complications

\begin{tabular}{lc}
\hline Complications & Number of patients [\%] \\
\hline Minor complication & $3[18]$ \\
Atrial fibrillation & 2 \\
Anemia & 1 \\
Major complication & $3[18]$ \\
Empyema & 2 \\
Hemothorax & 1 \\
\hline
\end{tabular}

disease over the time until becoming almost anecdotic in the last decade.

\section{The concept of oligometastic disease, prognostic factors and their implication on pneumonectomy}

In 1965, Thomford emphasized the role of pulmonary metastasectomy to improve survival (21) including the use of extended surgery-i.e., pneumonectomy-as salvage procedure. The concept of "oligometastases" was introduced in 1995 by Hellman and Weichselbaum (22). The advances in imaging technology (23), the routinely use of pet-scanner for staging (24), the better comprehension of differential patterns of metastatic spread (25) with regards to molecular biology, pathogenesis and response to treatments, allowed to a novel interpretation of the metastatic disease and a better selection of oligometastatic patients. Careful selection of surgical candidates represents the key to success for surgery and expected long-term disease-free survival. Current recognized oncological criteria to consider surgical resection for lung metastases include (3): (I) the primitive cancer needs to be controlled or controllable, (II) no extrathoracic metastases- that is not controlled or controllableexist (III) all of the lesions must be resectable, with adequate pulmonary reserve and (IV) there are no alternative potentially curative medical treatments with lower morbidity. Several different prognostic factors and clinical predictors has been investigated: age and performance status of the patient, disease-free interval, number and size of metastases, histological type, lymph node assessment, positive response to adjuvant medical treatment, previous lung resections, biomarkers quantification and more recently, genotype and mutational burden (26-30). All these features are nowadays part of the multidisciplinary 
decision-making to identify patients who can benefit from pulmonary metastasectomy and those who should spare unnecessary loss of lung parenchyma. Even if the studies presented in the literature are conflicting (31), the ideal patient for surgical metastasectomy with curative intent has a good performance status, normal pulmonary function tests and presents, after a long disease-free interval, one — or very few-pulmonary lesions with no detectable lymph node involvement and normal—or at least low-tumor specific markers if existing; all the metastatic disease should be totally resectable with the sacrifice of a very limited volume of parenchyma-i.e., wedge resection or segmentectomy, preferably performed using minimally invasive surgery (32).

In a speculative fashion, patients evaluated for pneumonectomy to accomplish a curative metastasectomy rarely meet these criteria. However, the above-mentioned features do not represent strict inclusion principles for surgical resection of pulmonary secondary lesions. Indeed, even if the acquired knowledge of oligometastatic state has widely reduced the number of patients eligible for extended resections and thus the number of patients eligible for pneumonectomy, the presence in the literature of sporadic long-term survival patients after extended resections have not completely excluded pneumonectomy to have a therapeutic role. Nevertheless, the massive improvements in systemic therapies and in locoregional ablation techniques have contributed to the relative disappearance of pneumonectomy as preferable surgical approach to treat metastases.

\section{Modern therapeutic alternatives: improved medical treatments and non-surgical ablative therapies}

Over the last few decades, neoadjuvant and adjuvant chemotherapeutic regimens have radically evolved, based on specific patient characteristics, tumor biology, and drug efficacy (33).

Improvements in systemic therapy has deeply changed the course of metastatic disease in all cancer types and have also altered the role of surgery as demonstrated in the management of germ cell tumor (34), breast cancer (35), melanoma (36) or renal cell carcinoma (37) with a high longterm cure rate and clinically meaningful durable objective responses. As a result, systemic treatments have reduced the pool of patients previously addressed for extended resections, proposing an alternative to control otherwise rapidly fatal diseases. Nevertheless, it is unlikely that advanced medical treatments will render metastasectomy obsolete. In fact, systemic therapy may enable a subset of patients with advanced metastatic cancer who exhibit incomplete tumor response and develop residual drug-resistant clones to be considered for curative surgery. Moreover, most solid tumors that metastasize to the lung are still relatively insensitive to currently available therapies, notably sarcoma (38) and colorectal carcinoma (39). Image-guided ablative therapies including radiofrequency ablation (40), cryoablation (41), microwave ablation (42), and laser-induced thermal therapy and stereotactic body radiation therapy (SBRT) (43), have also emerged as potential alternative to surgical resection (44) showing survival rates comparable to those reported for surgical resection $(45,46)$. In 2015 a large French study published by de Baère (47) reported a multicenter series of 566 patients treated by radiofrequency ablation for lung metastases up to $7 \mathrm{~cm}$, with a 5 -year overall survival rate for colon cancer, rectal cancer, kidney and sarcoma of $56 \%$, $49.6 \%, 53.8 \%$ and $42 \%$ respectively. The major criticism to thermal ablation results the relative low efficacy in centrally located lesions (48) but SBRT seems to overcome this obstacle (49) with a reported 2-year overall survival of $49.6 \%$ in 66 patients treated for centrally located metastatic lesions, with very low mortality and morbidity rates. In current practice, image-guided ablation and stereotactic ablative radiotherapy (SABR) are two valid alternatives to surgery in patients with compromised respiratory function or showing major comorbidities. They certainly represent also a valid alternative to surgery in centrally located metastases whose resection would necessitate a pneumonectomy.

\section{Conclusions}

Pneumonectomy for lung metastasectomy has been used as a last resort to treat advanced metastatic disease in the pre-modern era, even if its role has always been strongly debated and discouraged. High mortality and morbidity rates and the relatively poor oncological benefit along with a better comprehension of the mechanism of metastases, stricter preoperative criteria for patient selection and the progress of effective therapeutic alternatives have drastically reduced potential indications for pneumonectomy to resect pulmonary secondary lesions. Nevertheless, oligometastatic state still represents a dynamic and controversial terrain. The presence of rare long-term survival patients in our retrospective collection as well as in the literature suggests that pneumonectomy must not be excluded a priori but deserves to be carefully considered in a multidisciplinary 
management. In the absence of appropriate randomized trials comparing extended surgical resection versus SABR, versus percutaneous ablation versus systemic therapy, any option aimed to cure oligometastatic disease should be considered and pneumonectomy may remain an option.

\section{Acknowledgments}

Funding: None.

\section{Footnote}

Provenance and Peer Review: This article was commissioned by the Guest Editors (Lorenzo Spaggiari and Luca Bertolaccini) for the series "The Role of Pneumonectomy in Thoracic Surgery in The Third Millennium" published in Shangbai Chest. The article has undergone external peer review.

Conflicts of Interest: All authors have completed the ICMJE uniform disclosure form (available at http://dx.doi. org/10.21037/shc.2019.12.04). The series "The Role of Pneumonectomy in Thoracic Surgery in The Third Millennium" was commissioned by the editorial office without any funding or sponsorship. The authors have no other conflicts of interest to declare.

Ethical Statement: The authors are accountable for all aspects of the work in ensuring that questions related to the accuracy or integrity of any part of the work are appropriately investigated and resolved.

Open Access Statement: This is an Open Access article distributed in accordance with the Creative Commons Attribution-NonCommercial-NoDerivs 4.0 International License (CC BY-NC-ND 4.0), which permits the noncommercial replication and distribution of the article with the strict proviso that no changes or edits are made and the original work is properly cited (including links to both the formal publication through the relevant DOI and the license). See: https://creativecommons.org/licenses/by-nc-nd/4.0/.

\section{References}

1. Pastorino U, Buyse M, Friedel G, et al. Long-term results of lung metastasectomy: prognostic analyses based on 5206 cases. J Thorac Cardiovasc Surg 1997;113:37-49.
2. Åberg T, Treasure T. Analysis of pulmonary metastasis as an indication for operation: an evidence-based approach. Eur J Cardiothorac Surg 2016;50:792-8.

3. Erhunmwunsee L, Tong BC. Preoperative evaluation and indications for pulmonary metastasectomy. Thorac Surg Clin 2016;26:7-12.

4. Higashiyama $M$, Tokunaga $T$, Nakagiri $T$, et al. Pulmonary metastasectomy: outcomes and issues according to the type of surgical resection. Gen Thorac Cardiovasc Surg 2015;63:320-30.

5. Bernard A, Deschamps C, Allen MS, et al. Pneumonectomy for malignant disease: factors affecting early morbidity and mortality. J Thorac Cardiovasc Surg 2001;121:1076-82.

6. Cardillo G, Galetta D, van Schil P, et al. Completion pneumonectomy: a multicentre international study on 165 patients. Eur J Cardiothorac Surg 2012;42:405-9.

7. Tabutin M, Couraud S, Guibert B, et al. Completion pneumonectomy in patients with cancer: postoperative survival and mortality factors. J Thorac Oncol 2012;7:1556-62.

8. Putnam JB Jr, Suell DM, Natarajan G, et al. Extended resection of pulmonary metastases: is the risk justified? Ann Thorac Surg 1993;55:1440-6.

9. Spaggiari L, Grunenwald DH, Girard P, et al. Pneumonectomy for lung metastases: indications, risks, and outcome. Ann Thorac Surg 1998;66:1930-3.

10. Koong HN, Pastorino U, Ginsberg RJ. Is there a role for pneumonectomy in pulmonary metastases? International Registry of Lung Metastases. Ann Thorac Surg 1999;68:2039-43.

11. Hendriks JM, van Putte B, Romijn S, et al. Pneumonectomy for lung metastases: report of ten cases. Thorac Cardiovasc Surg 2003;51:38-41.

12. Casiraghi M, Maisonneuve P, Brambilla D, et al. The role of extended pulmonary metastasectomy. J Thorac Oncol 2015;10:924-9.

13. Matsutani N, Okumura S, Yoshino I, et al. Pneumonectomy in pulmonary metastasis. J Thorac Dis 2017;9:4523-30.

14. Grunenwald D, Spaggiari L, Girard P, et al. Completion pneumonectomy for lung metastases: is it justified? Eur J Cardiothorac Surg 1997;12:694-7.

15. Jungraithmayr W, Hasse J, Stoelben E. Completion pneumonectomy for lung metastases. Eur J Surg Oncol 2004;30:1113-7.

16. Chataigner O, Fadel E, Yildizeli B, et al. Factors affecting early and long-term outcomes after 
completion pneumonectomy. Eur J Cardiothorac Surg 2008;33:837-43.

17. Dear RF, Kelly PJ, Wright GM, et al. Pulmonary metastasectomy for bone and soft tissue sarcoma in Australia: 114 patients from 1978 to 2008. Asia Pac J Clin Oncol 2012;8:292-302.

18. Inoue M, Ohta M, Iuchi K, et al. Benefits of surgery for patients with pulmonary metastases from colorectal carcinoma. Ann Thorac Surg 2004;78:238-44.

19. Lin AY, Kotova S, Yanagawa J, et al. Risk stratification of patients undergoing pulmonary metastasectomy for soft tissue and bone sarcomas. J Thorac Cardiovasc Surg 2015;149:85-92.

20. Cheung FP, Alam NZ, Wright GM. The past, present and future of pulmonary metastasectomy: a review article. Ann Thorac Cardiovasc Surg 2019;25:129-41.

21. Thomford NR, Woolner LB, Clagett OT. The surgical treatment of metastatic tumors in the lungs. J Thorac Cardiovasc Surg 1965;49:357-63.

22. Hellman S, Weichselbaum RR. Oligometastases. J Clin Oncol 1995;13:8-10.

23. Kang MC, Kang CH, Lee HJ, et al. Accuracy of 16-channel multi-detector row chest computed tomography with thin sections in the detection of metastatic pulmonary nodules. Eur J Cardiothorac Surg 2008;33:473-9.

24. Zhu A, Lee D, Shim H. Metabolic positron emission tomography imaging in cancer detection and therapy response. Semin Oncol 2011;38:55-69.

25. Chiang AC, Massagué J. Molecular basis of metastasis. N Engl J Med 2008;359:2814-23.

26. Friedel G, Pastorino U, Ginsberg RJ, et al. Results of lung metastasectomy from breast cancer: prognostic criteria on the basis of 467 cases of the International Registry of Lung Metastases. Eur J Cardiothorac Surg 2002;22:335-44.

27. Pfannschmidt J, Klode J, Muley T, et al. Nodal involvement at the time of pulmonary metastasectomy: experiences in 245 patients. Ann Thorac Surg 2006;81:448-54.

28. Casiraghi M, De Pas T, Maisonneuve P, et al. A 10-year single-center experience on 708 lung metastasectomies: the evidence of the "international registry of lung metastases". J Thorac Oncol 2011;6:1373-8.

29. Moumtzi D, Lampaki S, Zarogoulidis P, et al. Prognostic factors for long term survival in patients with advanced non-small cell lung cancer. Ann Transl Med 2016;4:161.
30. Corsini EM, Mitchell KG, Mehran RJ, et al. Colorectal cancer mutations are associated with survival and recurrence after pulmonary metastasectomy. J Surg Oncol 2019;120:729-35.

31. Palma DA, Salama JK, Lo SS, et al. The oligometastatic state - separating truth from wishful thinking. Nat Rev Clin Oncol 2014;11:549-57.

32. Gossot D, Radu C, Girard P, et al. Resection of pulmonary metastases from sarcoma: can some patients benefit from a less invasive approach? Ann Thorac Surg 2009;87:238-43.

33. Dy GK, Hobday TJ, Nelson G, et al. Long-term survivors of metastatic colorectal cancer treated with systemic chemotherapy alone: a north central cancer treatment group review of 3811 patients, n0144. Clin Colorectal Cancer 2009;8:88-93.

34. Levi JA, Raghavan D, Harvey V, et al. The importance of bleomycin in combination chemotherapy for goodprognosis germ cell carcinoma. Australasian Germ Cell Trial Group. J Clin Oncol 1993;11:1300-5.

35. Jin L, Han B, Siegel E, et al. Breast cancer lung metastasis: molecular biology and therapeutic implications. Cancer Biol Ther 2018;19:858-68.

36. Hodi FS, Chiarion-Sileni V, Gonzalez R, et al. Nivolumab plus ipilimumab or nivolumab alone versus ipilimumab alone in advanced melanoma (CheckMate 067): 4-year outcomes of a multicentre, randomised, phase 3 trial. Lancet Oncol 2018;19:1480-92.

37. Larkin JM, Kipps EL, Powell CJ, et al. Systemic therapy for advanced renal cell carcinoma. Ther Adv Med Oncol 2009;1:15-27.

38. Nielsen OS, Blay JY, Judson IR, et al. Metastatic soft tissue sarcoma in adults: prognosis and treatment options. Am J Cancer 2003;2:211-21.

39. Shah SA, Haddad R, Al-Sukhni W, et al. Surgical resection of hepatic and pulmonary metastases from colorectal carcinoma. J Am Coll Surg 2006;202:468-75.

40. Hiyoshi Y, Miyamoto Y, Kiyozumi Y, et al. CTguided percutaneous radiofrequency ablation for lung metastases from colorectal cancer. Int J Clin Oncol 2019;24:288-95.

41. Inoue M, Nakatsuka S, Yashiro H, et al. Percutaneous cryoablation of lung tumors: feasibility and safety. J Vasc Interv Radiol 2012;23:295-302; quiz 305.

42. Wolf FJ, Grand DJ, Machan JT, et al. Microwave ablation of lung malignancies: effectiveness, CT findings, and safety in 50 patients. Radiology 2008;247:871-9. 
43. Takeda A, Kunieda E, Ohashi T, et al. Stereotactic body radiotherapy (SBRT) for oligometastatic lung tumors from colorectal cancer and other primary cancers in comparison with primary lung cancer. Radiother Oncol 2011;101:255-9.

44. Vogl TJ, Eckert R, Naguib NN, et al. Thermal ablation of colorectal lung metastases: retrospective comparison among laser-induced thermotherapy, radiofrequency ablation, and microwave ablation. AJR Am J Roentgenol 2016;207:1340-9.

45. Treasure T. Surgery and ablative techniques for lung metastases in the Pulmonary Metastasectomy in Colorectal Cancer (PulMiCC) trial: is there equivalence? J Thorac Dis 2016;8:S649-51.

46. Schlijper RC, Grutters JP, Houben R, et al. What to choose as radical local treatment for lung metastases

doi: 10.21037/shc.2019.12.04

Cite this article as: Mariolo AV, Grigoroiu M, SeguinGivelet A, Brian E, Gossot D, Girard P. Pneumonectomy for lung metastases: the role in the modern era. Shanghai Chest $2020 ; 4: 18$. from colo-rectal cancer: surgery or radiofrequency ablation? Cancer Treat Rev 2014;40:60-7.

47. de Baère T, Aupérin A, Deschamps F, et al. Radiofrequency ablation is a valid treatment option for lung metastases: experience in 566 patients with 1037 metastases. Ann Oncol 2015;26:987-91.

48. Yan TD, King J, Sjarif A, et al. Percutaneous radiofrequency ablation of pulmonary metastases from colorectal carcinoma: prognostic determinants for survival. Ann Surg Oncol 2006;13:1529-37.

49. Davis JN, Medbery C, Sharma S, et al. Stereotactic body radiotherapy for centrally located early-stage non-small cell lung cancer or lung metastases from the RSSearch $\left({ }^{\circledR}\right)$ patient registry. Radiat Oncol 2015;10:113. 